
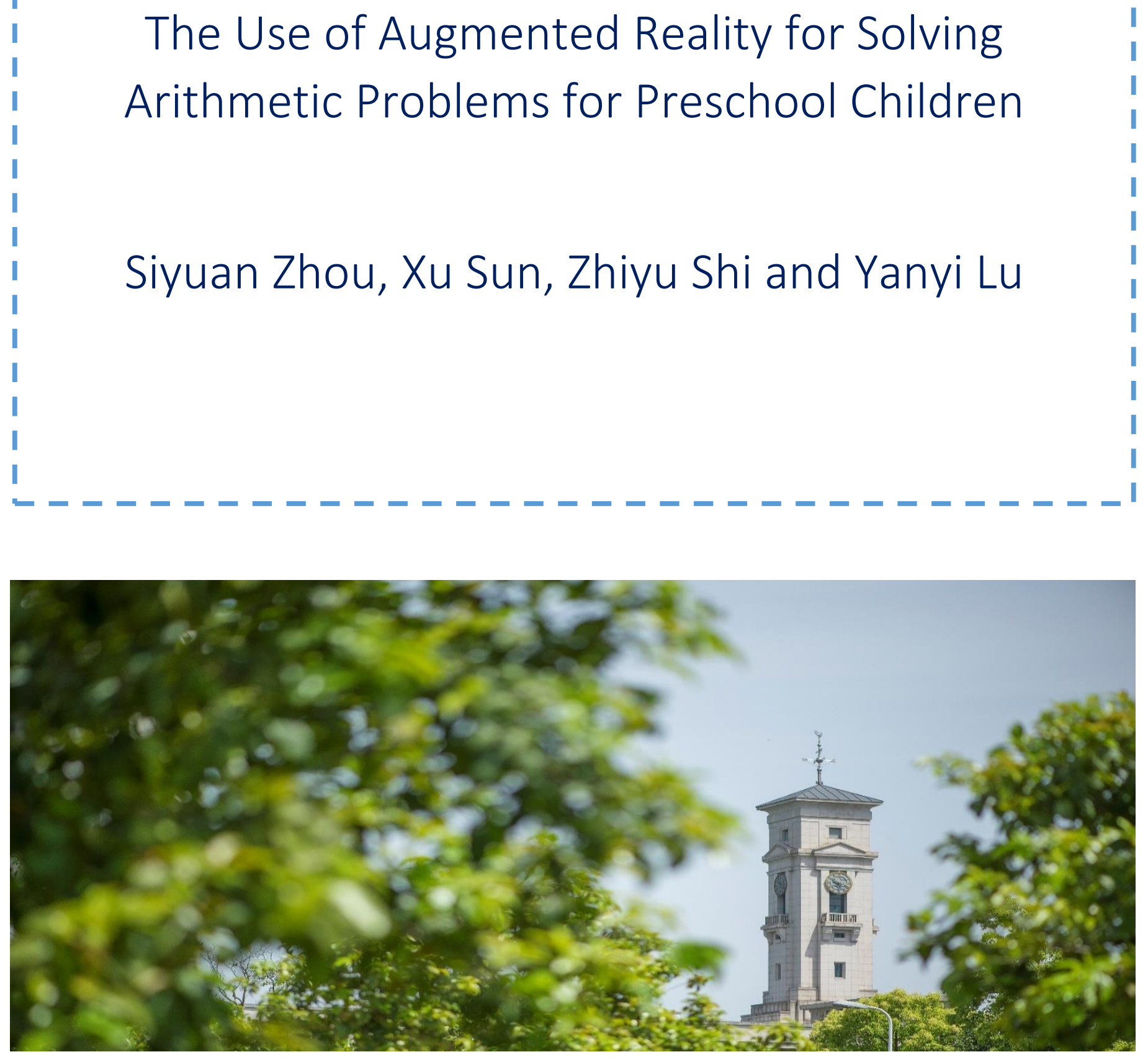
University of Nottingham Ningbo China, 199 Taikang East Road, Ningbo, 315100, Zhejiang, China.

First published 2020

This work is made available under the terms of the Creative Commons Attribution 4.0 International License:

http://creativecommons.org/licenses/by/4.0

The work is licenced to the University of Nottingham Ningbo China under the Global University Publication Licence:

https://www.nottingham.edu.cn/en/library/documents/researchsupport/global-university-publications-licence-2.0.pdf 


\title{
The Use of Augmented Reality for Solving Arithmetic Problems for Preschool Children
}

\author{
Siyuan Zhou ${ }^{[0000-0002-1276-4177]}$ Xu Sun ${ }^{[0000-0002-2340-7095]}$, Zhiyu Shi and Yanyi Lu \\ University of Nottingham Ningbo China, 199 Taikang East Road, \\ Ningbo, 315100, China \\ \{siyuan.zhou, xu.sun\} @nottingham.edu.cn \\ \{zy18438, zy19436\}@alumni.nottingham.edu.cn
}

\begin{abstract}
Preschool children are required to acquire problem-solving ability and related time and sequence concepts to solve mathematical story problems. The maturation and pervasion of disruptive technologies, such as augmented reality (AR), may help preschool children to better acquire this knowledge and skills. However, it is still unknown how preschoolers would make use of AR as a learning tool for tackling arithmetic story problems with the involvement of the concepts of time and sequence. Consequently, the present study attempted to employ direct observation and interview methods to compare and gain insights into young children's learning behaviors under traditional 2D pictorial and AR contexts. In line with the early development trajectories of a normal child aged 4-6 years old, a series of planned arithmetic problems which primarily comprised seriation (e.g. first, second, third) and scheduling (e.g. arriving, leaving) concepts were structured in scenario-based stories and designed specifically for preschool children. The findings of the current study reveal that AR intervention may well develop the problem-solving and independent mathematical thinking ability for preschool children by encouraging them to consider all information involved in the story problems, rather than simply guessing the answer from a $2 \mathrm{D}$ pictorial mode. Finally, based on the fact that the majority of preschool children still rely on a concrete counting method, the recommendation is to integrate AR technology into the traditional pictorial scenarios for the purpose of supporting the development of children's ability to solve arithmetic story problems.
\end{abstract}

Keywords: Augmented reality, Preschool children, Problem solving, Time and sequence

\section{Introduction}

Problem solving is an essential mathematical ability for preschool-aged children to achieve school readiness and later academic success [1][2]. It comprises primarily the synthesis of already acquired knowledge in "representing a situation mathematically, devising a strategy to solve the problem, carrying out the solution, and reflecting on the answer" (p.153) [3]. As suggested by several researchers, the inclusion of arithmetic story problems within the kindergarten curriculum can encourage young children to 
establish connections between conceptual and mathematical knowledge [4], as well as integrating these practices into real-life scenarios [3][4]. In addition to regular classes, preschool children are also often exposed to natural mathematics learning contexts informally in daily routines, such as by participating in various pedagogic activities, as instructed by their family [5].

As one vital constituent element, the concepts of time and sequence typically provide a chronological structure for problem-solving [2][6]. Such knowledge starts to develop at a young age [2] and often serves as a foundation for preschoolers to solve more complicated story problems and cultivate higher-order mathematical thinking [1]. Nunes and Moreno [7] have highlighted how poor problem-solving performance by preschoolaged children is closely associated with weaknesses in their learning and understanding of time and sequence. These concepts are abstract and lack any tangible references, thus making them more difficult for preschoolers to process than concrete concepts, such as colors and shapes [8]. The study by Ponari et al. [9] provided evidence that abstract words acquired by four-year-old children accounted for less than $10 \%$ of their total vocabulary, rising to approximately $20 \%$ by the age of six. Moreover, Gleitman et al. [10] also proposed a further explanation for the difficulty of abstract word acquisition, indicating that the lexical formatives of children are largely based on their perception of the surrounding environment so that sufficient linguistic experience was demanded for preschoolers prior to their understanding of abstract concepts.

On this basis, the maturation and pervasion of disruptive technologies in the current era, such as virtual reality (VR) and augmented reality (AR), are likely to help preschool children to better acquire the knowledge and problem-solving skills mentioned above. A previous research by Eden [11] demonstrated the huge potential for applying VR technology to improve the sequential time perception of normal young children. It was found that immersion in multi-sensory learning contexts would facilitate the conversion of abstract concepts into something more concrete, thus helping preschoolers to better understand abstract words. Based on the fact that, for safety reasons, commercial VR headsets are not usually recommended to be used by children under the age of 13 years [12], AR is regarded as an effective and safe alternative for early childhood education. According to Azuma et al. [13], an AR system "supplements the real world with virtual (computer-generated) objects that appear to coexist in the same place as the real world" (p.34). Unlike VR, which provides a completely virtual world as its backdrop and main content, the dominant perception of AR users is still located within a realistic environment but blended with virtual content [14]. Although in theory the main features of VR, including interactivity, immersion and sensitivity of information, can be similarly achieved in AR [14], it is reasonable to assume that the objectively existing differences between $A R$ and VR, such as varying degrees of immersion, may present different impacts on the learning performance of young children. As a consequence, it is necessary to investigate whether AR technology would contribute to the acquisition of time and sequence concepts for preschoolers in similar patterns within the frame of arithmetic story problems.

Meanwhile, recent studies have explored AR and its influence on mathematics education in early childhood, including the learning of subitizing and equipartitioning [15] and geometry [16]. The main purpose of these studies was to examine whether it was 
possible to improve the relative mathematical skills of children through the use of AR technology. For instance, Gecu-Parmaksiz and Delialioglu [16] compared the traditional method (i.e. physical manipulatives) to AR based virtual manipulatives in teaching geometry for preschool-aged children. The findings of their research revealed that AR intervention was more effective than physical manipulatives in supporting target groups to understand geometric shapes. Nevertheless, in the field of early childhood mathematics education, the effect of AR on helping preschoolers to solve arithmetic story problems still remain unknown and deserve to be further investigated. Consequently, this study attempted to employ direct observation and interview techniques to compare and gain insights into preschoolers' learning behaviors under traditional 2D pictorial and AR contexts when tackling mathematical story problems with the involvement of essential time and sequence concepts.

\section{Methods}

\subsection{Participants}

The participants in this study were 33 preschool children ( 16 males, 17 females, with ages ranging from 58 months to 77 months, $\mathrm{M}=64.12$; $\mathrm{SD}=3.89$ ) who had been invited from a public kindergarten in Ningbo, China. They all received formal kindergarten education systematically and were randomly chosen to prevent uncontrolled factors from influencing the results.

\subsection{Intervention Design}

Arithmetic Story Problems. Owing to the age characteristics of the participants, the mathematical problems that young children are able to solve are limited [4]. Therefore, the difficulty level of the arithmetic story problems featured in this study complies with the early development trajectories of a normal child aged 4-6 years old [2]. With regard to problem-solving skills, a preschool-aged child progresses from identifying sums up to five and their subtraction counterparts with objects mentally (4-year-old level), to solving relatively simple mathematical story problems with concrete counting methods (5-year-old level), to tackling repeated addition problems with more sophisticated strategies (6-year-old level). Furthermore, based on early childhood conceptual standards [6], it was highlighted by Schafer [17] that the following four sub-domains in the category of time/ sequence could be difficult for preschool-aged children to understand: temporal absolutes (e.g. never, always); scheduling (e.g. arriving, leaving, early, late); temporal nuances (e.g. young, old) and seriation (e.g. first, second, third).

As shown in Table 1, a series of planned problem-solving tasks, which include principally scheduling and seriation concepts with two different levels of complexity, were structured for preschool children exclusively. This should help to assess participants with varying degrees of mathematical ability, and help to avoid certain coincidental occasions, such as the correct answer being guessed. Within this framework of mathematical story problems, we attempted to examine the effects of AR intervention by 
comparing it with traditional 2D pictorial representation and then evaluating the performance of preschoolers before and after the exposure to the AR-based learning environment. Since Perihan [4] suggested that children can respond more easily to mathematical problems in word format rather than using symbols (e.g. plus and minus signs), only pictures and animations excluding symbols and text were presented to the participants. All of the story problems were delivered verbally by the researchers.

Moreover, according to Perihan [4], word problems can be divided into four groups as follows: joining, separating, comparing and part-part-whole. In this case, only the first three types of word problems were included. In a join problem (i.e. using an addition operation), there are three fundamental elements: the initial, the change (the part being added) and the result (the largest amount). In a separate problem (i.e. using a subtraction operation), the initial amount is normally the whole while the change refers to the difference in a quantity from the initial quantity. Furthermore, in a compare problem, it often consists of the comparison of two amounts. The third element is the difference between these two already-given quantities. On this basis, one of the elements (e.g. the result) can be the unknown part in the various types of story problems.

Table 1. Structure of arithmetic story problems.

\begin{tabular}{|c|c|}
\hline Task groups & Problem types and story scripts (English version) \\
\hline \multirow{2}{*}{$\begin{array}{l}\text { Task } 1 \\
\text { Seriation concepts: } \\
\text { First, second }\end{array}$} & $\begin{array}{l}\text { 1.1 Separate problem (result unknown) with a single-step } \\
\text { calculation (easy): There were } 7 \text { carrots in the ground. } \\
\text { First, the rabbit took } 2 \text { carrots. How many carrots are } \\
\text { left in the ground now? }\end{array}$ \\
\hline & $\begin{array}{l}\text { 1.2 Separate problem (result unknown) with a two-step } \\
\text { calculation (complex): There were } 9 \text { candies in the jar. } \\
\text { First, the piglet took } 3 \text { candies. Second, the kitty took } \\
\text { another } 2 \text { candies. How many candies are left now? }\end{array}$ \\
\hline \multirow{2}{*}{$\begin{array}{l}\text { Task } 2 \\
\text { Scheduling concepts: } \\
\text { Arriving, leaving }\end{array}$} & $\begin{array}{l}\text { 2.1 Join problem (result unknown) with a single-step cal- } \\
\text { culation (easy): There were } 2 \text { cars on the road. Then } 4 \\
\text { more cars arrived. How many cars are there on the road } \\
\text { now? }\end{array}$ \\
\hline & $\begin{array}{l}\text { 2.2 Separate-Join problem (result unknown) with a two- } \\
\text { step calculation (complex): There were } 7 \text { planes in the } \\
\text { sky. } 4 \text { planes left, and then } 3 \text { more planes arrived. How } \\
\text { many planes are there in the sky now? }\end{array}$ \\
\hline $\begin{array}{l}\text { Task } 3 \\
\text { Scheduling concepts: } \\
\text { Early, late }\end{array}$ & $\begin{array}{l}\text { 3.1 Compare problem (later unknown) with a single-step } \\
\text { calculation: Two people departed from the same place } \\
\text { at the same time by car and bicycle, respectively. The } \\
\text { car driver spent } 2 \text { units of time to reach the destination. } \\
\text { The cyclist arrived } 3 \text { units of time later than the car } \\
\text { driver. How many units of time did it take the cyclist to } \\
\text { reach the destination? }\end{array}$ \\
\hline
\end{tabular}


Pictorial Mode of Representation. Five pictorial scenarios were designed, corresponding to the tasks listed above. Each scenario comprised several 2D still pictures forming an arithmetic story problem with relative time and sequencing concepts. For example, the script for task 1.1 was divided into two episodes as presented in Figure 1. The first episode illustrated 7 carrots in the field while the second depicted 2 carrots being taken away by a rabbit. The remaining number of carrots in the ground was blurred in the second episode in order to prevent the participants from counting directly to obtain the answer without clearly understanding the problem itself.
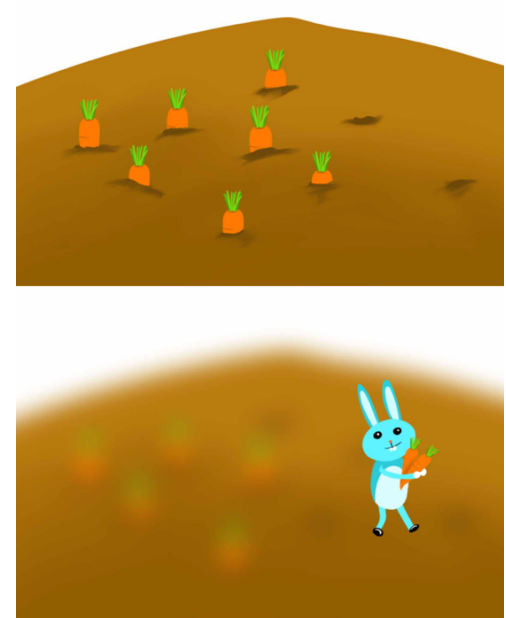

Fig. 1. Images for the pictorial mode (Task 1.1)

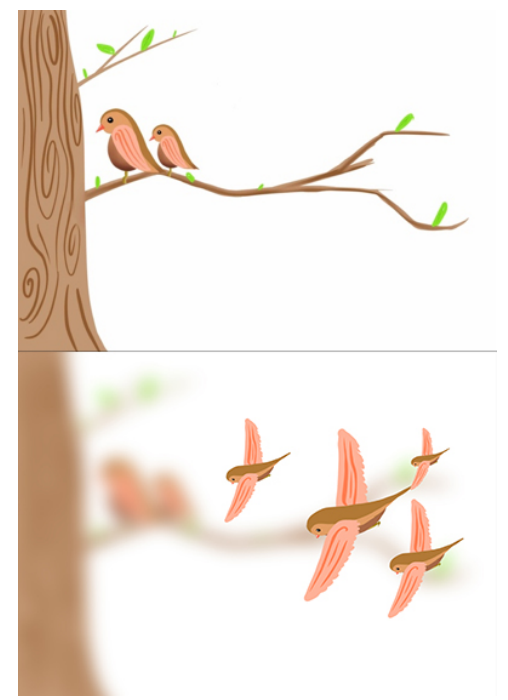

Fig. 2. Images for the AR mode (Task 2.1) 
AR Mode of Representation. With regard to the design of AR intervention, 2D and 3D animation were the two most common methods employed to generate the initial scenarios (i.e. what is known as content). As suggested by Kataja [18], the flat 2D animations were considered to be less immersive and attractive than the 3D models, but they have significant advantages in terms of budgets and time consumption. 2D animation may be preferable if viewing a character (or model) at different angles does not add any distinct value, particularly in the early exploration stage. Therefore, this project began with 2D animation for the building of scenarios as guided by the above scripts (see Table 1). The animations were then exported in a video file format, in preparation for being integrated into augmented reality apps. There are several such apps available on the market which allow for the achievement of AR functions, such as Google Glass, Unity, Aris and Aurasma. This technology is delivered via two practices: 1) scanning with a camera on a mobile device; 2) equipping with a head mounted display (HMD). The research by Parton [19] indicated that there were no real learning differences between two groups of children who used a mobile device (i.e. an iPad) and a HMD (i.e. Google Glass) respectively. As a consequence, when taking the cost and accessibility of equipment into account, a mobile device featuring an interactive AR app generated by Unity was utilized in this project. The video file for each scenario was then positioned over an image target (i.e. the first episode) through the Unity platform. The new AR app created by Unity was dependent on image recognition technology. By scanning the image target via a mobile device, the participants were able to see the AR content of $2 \mathrm{D}$ animation merged with the surroundings on the display screen.

Moreover, the main characters in each AR scenario were altered to provide the participants with a fresh story background. Other variables, including the problem types and their related algorithms, remained the same. For example, the scenario of task 2.1 changed from featuring cars to featuring birds. Based on the above script (see Table 1), the first episode presented two birds in the tree, while the second depicted another four birds arriving. The participants were required to calculate the total number of birds in the tree ultimately. Similarly, only the process of birds moving, rather than direct results, were presented to the participating children.

\subsection{Procedure}

After gaining approval from the research ethics committee at the University of Nottingham Ningbo China, as well as the consent of kindergarten teachers, 33 Chinese preschool children aged 4-6 years were recruited. Each participant followed the same sixstep activity structure shown below.

Step 1. For task 1, prior to being exposed to the pictorial mode of representation, each child was first assessed to check whether s/he had acquired the seriation concepts or not. For example, the researcher would ask each participant which character had obtained the candy first, second and third, by showing him/her the storyboard (see Figure 3) and verbally narrating the story. The answer was recorded as true or false.

Step 2. In the pictorial scenario of task 1.1, the researcher first placed two images (see Figure 1) in front of the child and then described the mathematical story problem. Each participant was required to calculate the number of carrots remaining in the field. 


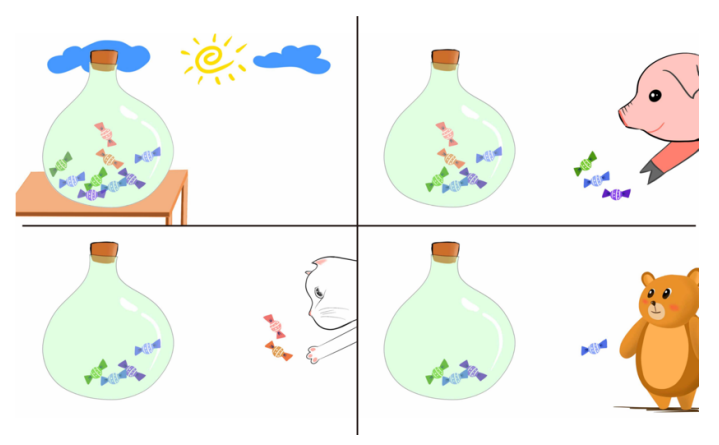

Fig. 3. Storyboard to assess the concept acquisition level of the participants

As the principal criteria for evaluating the problem-solving skills of the children, their answers and response times were recorded. In addition, the question "who was the first to take away a carrot?" was asked to ascertain the child's understanding of related sequential concepts.

Step 3. In the AR scenarios, the still images with altered story backgrounds, as well as the AR content containing $2 \mathrm{D}$ animation on a mobile phone, were both provided to the participants. Similar to step 2, responses to the problem and the seriation concept were all recorded.

Step 4. Repeat steps 2-3 for task 1.2.

Step 5. Repeat steps 1-4 for tasks 2 and 3.

Step 6. At the end of activity, the researcher was able to gather each child's subjective opinions with regard to their preferred mode of representation. The recorded interview results were later analyzed via NVivo software in order to identify key insights from their answers.

\section{Results}

The results of the observations reveal that the majority of participating children did not fully understand the story problems or concepts in the 2D pictorial mode. They tended to seek answers directly from the pictures in the final episode of each scenario, and neglected the other information provided beforehand. For example, with regard to task 2.1 , the initial two cars staying in front of a house were blurred and only the four additional cars were depicted arriving at that house in the second episode. Although the researchers had explained the story problem unambiguously to the respondents, some still thought that there would ultimately be four cars (the correct answer was six) in total in front of the house, simply based on what they had seen in the final episode. In contrast, under the AR mode, the participants exhibited better acquisition of the concepts of time and sequence, and they were more likely to take into account all the information involved in the narrative to solve the problems. In addition, it was noticeable that some of the children still relied heavily on a concrete counting strategy and were inclined to look again at the pictures to answer the questions after watching the AR content. For instance, once the children knew the process of birds arriving at the roost, 
they were accustomed to counting the number of birds on the still pictures to obtain the answer.

With regard to the results of the brief post-experiment interviews, $45.5 \%$ of participants $(n=15)$ were in favor of the 2D pictorial mode, while the remainder $(n=18)$ preferred the AR mode. Tables 2 and 3 summarize several key factors affecting the choices of the children regarding their preferred mode of representation. Due to age limitations, the children could only provide brief (or no) responses to this issue. It was, therefore, interesting to find that 2D still pictures were more intuitive for certain children, such as for those who relied largely on concrete counting strategies when solving the problems. As pointed out by two of the children:

"The picture did not move, so I could count the number on it directly." [P24]

"It was quicker for me to get the answer by looking at the 2D still pictures." [P14]

To our surprise, one participant also considered the potential threat to their eyesight caused by digital devices when determining their preference between the two modes.

“The pictorial mode was more beneficial for maintaining good eyesight." [P13]

By contrast, AR intervention was found to enable the interpretation of the contexts of the story problems and the abstract concepts more clearly in an animated style, thus promoting the understanding and motivation of the target user group. As stated by three respondents:

“AR was more interesting, and I enjoyed seeing the animation.” [P03]

"The objects will move." [P09]

"It was easier for me to understand." [P24]

Moreover, it is noteworthy that the current AR intervention may be less attractive and useful for some preschoolers who had relatively good mathematical ability. They mentioned that there was no necessity to see the full AR animation prior to answering the question.

“The AR mode was time-consuming and meaningless for me.” [P07]

Table 2. Reasons for choosing the 2D pictorial mode.

\begin{tabular}{|l|l|l|}
\hline & 2D Pictorial Mode & Mentioned by (No.) \\
\hline 1 & It was intuitive and quick to get the answer. & 4 \\
\hline 2 & It was good for my eyesight. & 1 \\
\hline
\end{tabular}

Table 3. Reasons for selecting the AR mode.

\begin{tabular}{|l|l|l|}
\hline & AR Mode & Mentioned by (No.) \\
\hline 1 & The AR animation was interesting. & 2 \\
\hline 2 & The objects created in the animation will move. & 2 \\
\hline 3 & It was easy to understand. & 3 \\
\hline
\end{tabular}




\section{Discussion}

By comparing the learning behaviors of preschool children under traditional 2D pictorial and AR scenarios, this study has revealed that AR intervention can, to some extent, help preschoolers to improve their acquisition of time and sequence concepts and further to enhance their ability to solve arithmetic story problems.

The first possible explanation for this relates to the capacity of AR to concretize abstract concepts. By integrating digital 2D animations into a user's physical world seamlessly and simultaneously, AR technology is capable of presenting and visualizing the essential time and sequence concepts (e.g. arriving and leaving) in an animated and concrete way to the target user. Therefore, young children can probably perceive these abstract concepts more clearly and easily in the AR mode. This is consistent with previous researches (e.g. [20]) on the application of AR in the field of education. The acquisition of these concepts can further help preschool children to better understand the problems presented in stories.

Secondly, it is evident that AR technology is able to encourage preschoolers to think in a deep and comprehensive way when they use a problem-solving approach to tackle arithmetic problems. The evidence in our study indicates that, in comparison with the 2D pictorial mode, the participating children were more inclined to take into account all the processes needed to respond to the problems under the AR mode, rather than merely focusing on seeking the correct answer from the picture in the last episode of a story sequence.

The third contributing factor may be that as a novel teaching tool, AR intervention can also improve the enthusiasm for learning, and the levels of attention and motivation of preschool children. The post-experiment interviews suggest that, although all participants showed their willingness to take part in both intervention programs, some preschoolers were more motivated by and interested in using AR technology. It is possible that interventions such as this can motivate young children owing to their novelty value. This finding is in accordance with previous studies (e.g. [8][16]) showing that there are high levels of motivation among young children when they are first exposed to AR technology.

However, it should also be noted that because of the differences in their mathematical ability, a number of the children preferred to choose a concrete counting strategy when solving the arithmetic problems. In fact, this is consistent with the early development trajectories of normal children aged 4-6 years old [2]. Hence, a brief animation shown on a mobile device may hinder their learning process. The physical learning materials still appear to exert an essential role in the problem-solving processes of this type of end users.

\section{$5 \quad$ Conclusion and Limitations}

In conclusion, AR intervention may well develop independent mathematical thinking ability for preschool children by encouraging them to consider all information involved in a problem, rather than simply guessing the answer from a 2D pictorial mode. One of 
the most significant features of AR is that it enables the conversion of abstract sequential concepts to those which are more concrete, thus helping young children to better understand such vocabulary within the frame of a mathematical story problem, and thereby further enhancing their problem-solving skills in an engaging way. Finally, based on the fact that the majority of preschool children continue to rely on a concrete counting method, the recommendation is to integrate AR technology into traditional pictorial scenarios to support the development of children's ability to solve arithmetic problems.

With regard to the limitations, only $2 \mathrm{D}$ animation was used for the AR content in this pilot study, in line with the time and budgetary constraints. The AR mode can be further developed, for instance, by importing 3D models or characters to enhance the immersion and interactivity between an AR-based mobile device and preschool children. Consequently, the effects of AR technology on facilitating preschoolers' ability to solve arithmetic story problems can be further explored in the future research.

\section{References}

1. Harrington, M., Desjardin, J. L. \& Shea, L. C.: Relationships between early child factors and school readiness skills in young children with hearing loss. Communication Disorders Quarterly 32(1), 50-62 (2010).

2. Pagliaro, C. M. \& Kritzer, K. L.: The math gap: A description of the mathematics performance of preschool-aged deaf/hard-of-hearing children. Journal of Deaf Studies and Deaf Education 18(2), 139-160 (2013).

3. Ansell, E. \& Pagliaro, C. M.: The relative difficulty of signed arithmetic story problems for primary level deaf and hard-of-hearing students. Journal of Deaf Studies and Deaf Education 11(2), 153-170 (2005).

4. Perihan, D. A.: Preschool children skills in solving mathematical word problems. Educational Research and Reviews 10(18), 2539-2549 (2015).

5. Kritzer, K. L.: Families with young deaf children and the mediation of mathematically based concepts within a naturalistic environment. American annals of the deaf 153(5), 474-483 (2008).

6. Bracken, B. A. \& Crawford, E.: Basic concepts in early childhood educational standards: A 50-state review. Early Childhood Education Journal 37(5), 421-430 (2010).

7. Nunes, T. \& Moreno, C.: An intervention program for promoting deaf pupils' achievement in mathematics. Journal of Deaf Studies and Deaf Education 7(2), 120-133 (2002).

8. Eden, S. \& Ingber, S.: Virtual environments as a tool for improving sequence ability of deaf and hard of hearing children. American Annals of the Deaf 159(3), 284-295 (2014).

9. Ponari, M., Norbury, C. F. \& Vigliocco, G.: Acquisition of abstract concepts is influenced by emotional valence. Developmental Science 21(2), e12549 (2018).

10. Gleitman, L. R., Cassidy, K., Nappa, R., Papafragou, A. \& Trueswell, J. C.: Hard words. Language Learning and Development 1(1), 23-64 (2005).

11. Eden, S.: Enhancing children with hearing impairment with virtual reality (2010). http://homepage.divms.uiowa.edu/ hourcade/idc2012-specialneeds/eden.pdf, last accessed 2019/07/23.

12. Digital Trends, https://www.digitaltrends.com/virtual-reality/is-vr-safe-for-kids-we-askedthe-experts/, last accessed 2019/07/27.

13. Azuma, R., Baillot, Y., Behringer, R., Feiner, S., Julier, S. \& Macintyre, B.: Recent advances in augmented reality. IEEE Computer Graphics and Applications 21(6), 34-47 (2001). 
14. Yuen, S. C. Y., Yaoyuneyong, G. \& Johnson, E. Augmented reality: An overview and five directions for AR in education. Journal of Educational Technology Development and Exchange 4(1), 119-140 (2011).

15. Zanchi, C., Presser, A. L. \& Vahey, P.: Next generation preschool math demo: tablet games for preschool classrooms. In: Proceedings of the $12^{\text {th }}$ international conference on interaction Design and Children, pp. 527-530. ACM Press, New York, United States (2013).

16. Gecu-Parmaksiz, Z. \& Delialioglu, O.: Augmented reality-based virtual manipulatives versus physical manipulatives for teaching geometric shape to preschool children. British Journal of Educational Technology 50(6), 3376-3390 (2019).

17. Schafer, L.: Knowledge of basic concepts in deaf/hard of hearing children (2012). https://digitalcommons.wustl.edu/cgi/viewcontent.cgi?article=1653\&context=pacs_capston es, last accessed 2019/04/25.

18. Kataja, T.: 2D animation in the world of augmented reality (2019). https://www.theseus.fi/bitstream/handle/10024/172563/Kataja_Terhikki.pdf?sequence=2\&isAllowed=y, last accessed 2019/07/27.

19. Parton, B. S.: Glass vision 3D: digital discovery for the deaf. TechTrends 61(2), 141-146 (2017).

20. Ozdemir, M., Sahin, C., Arcagok, S. \& Demir, M. K.: The effect of augmented reality applications in the learning process: A MetaAnalysis study. Eurasian Journal of Educational Research 18, 1-22 (2018). 